\title{
МЕТОДИКА КОМПЛЕКСНОЙ ОЦЕНКИ ЭФФЕКТИВНОСТИ ПОТРЕБИТЕЛЬСКОГО ПОВЕДЕНИЯ В НАЦИОНАЛЬНОЙ ЭКОНОМИКЕ
}

\author{
(c) 2021 Махмудова Гулрух Равшанбековна \\ аспирант \\ Казанский (Приволжский) федеральный университет, Россия, Республика Татарстан, Казань \\ E-mail: happy-daisy@rambler.ru
}

В работе обоснована методика комплексной оценки эффективности потребительского поведения, которая дает возможность оценить эффективность потребительского поведения физических лиц в рамках экономической системы различного уровня (государство, регион, муниципальное образование) в контексте сопоставления параметров интенсивности изменения различных составляющих потребительского поведения с темпами развития смежных социально-экономических процессов, в первую очередь, генерирования доходов и темпов изменения производительности труда и занятости, а также определить на данной основе наиболее значимые резервы повышения уровня результативности потребительского поведения. Как показала апробация обоснованной автором методики, уровень эффективности потребительского поведения в национальной экономике РФ в целом в 2020 г. составил лишь 10,65\%, что, в соответствии с унифицированной шкалой предлагаемой методики, представляет собой неудовлетворительное значение. В значительной степени подобная ситуация была обусловлена недостаточностью денежных ресурсов большинства групп населения, необходимых для осуществления достаточного потребления товаров и услуг. Основные резервы повышения эффективности потребительского поведения, которые могут быть определены по критерию максимизации инверсии рангов, соответственно, являются: снижение уровня дифференциации доходов населения России, что за счет увеличения в его структуре среднего класса позволит последовательно увеличить потребление широкого спектра товаров и услуг повседневного спроса; обеспечение роста как реальных денежных доходов населения в целом, в т.ч. за счет дальнейшего прогрессивного развития института самозанятости, так и средней заработной платы, что, собственно, является объективной финансовой основой повышения эффективности потребительского поведения в национальной экономике; обеспечение дельнейшего роста результативности политики национального протекционизма, нацеленной на рост производства отечественных товаров, в первую очередь в сегменте высокотехнологичной продукции народного потребления.

Ключевые слова: потребительское поведение, предельная полезность, маржинализм, маркетинг, асимметричность информации.

Следует отметить, что одной из значимых аналитико-методических проблем является недостаточная проработанность вопроса о комплексной оценке экономической эффективности потребительского поведения при рассмотрении последнего на макро-, региональном или муниципальном уровне функционирования социально-экономической системы.

Вместе с тем, в отечественной экономической науке в конце 1980 гг. сформирован методический инструментарий системной оценки эффективности различного рода экономических явлений и процессов, основанный на мо- дификации методологии ранговой статистики. Изначально такого рода инструментарий, получивший название нормативной системы показателей (НСП), был сформирован И.М.Сыроежиным для комплексного анализа проблем обеспечения эффективности деятельности промышленного предприятия". Позднее, в 2010 гг., методический инструментарий НСП был трансформирован для комплексной оценки таких процессов, как, в частности, политика ресурсосбережения в промышленности (И.И.Гизятов" оценка результативности процесса воспроизводства основных фондов компании (Дж. Калу-

\footnotetext{
Сыроежин И. М. Система показателей эффективности и качества. - М.: Экономика, 1980

" Гизятов И.И. Формирование и комплексная оценка эффективности политики ресурсосбережения в промышленности: Автореф. дис.к.э.н. - Казань, 2011.С.13-15.
} 
би") и др. Вместе с тем, для оценки тенденций и проблем потребительского поведения методология построения нормативной системы социально-экономических показателей ранее не применялась.

Соответственно, нами предлагается методика комплексной оценки эффективности потребительского поведения индивидов в национальной экономике, основанная на модификации инструментария ранговой статистики в парадигме нормативной системы показателей.

Предлагаемая методика включает в себя следующие последовательные этапы:

1. Формирование эталонной последовательности темпов изменения социальноэкономических показателей, включенных в состав методики. В целом, эталонная последовательность темпов изменения социальноэкономических показателей, включенных в состав предлагаемой нами методики комплексной оценки экономической эффективности потребительского поведения, имеет следующий вид:

$1 /$ Kdd $>$ DD $>$ AZ $>$ S $>$ NP $>$ P $>$ V $>$ IS $>$ Z $(2.3 .1)$

где Kdd - темп роста коэффициента дифференциации доходов населения социальноэкономической системы (коэффициент фондов, децильный коэффициент), который представляет собой отношение легальных денежных доходов $10 \%$ наиболее и $10 \%$ наименее обеспеченных индивидов;

DD - темп роста средних денежных доходов населения социально-экономической системы;

$\mathrm{AZ}$ - темп роста среднего уровня заработной платы занятых в экономике соответствующего уровня (государства, региона, муниципального образования);

S - темп роста потребления услуг физическими лицами, в т.ч. банковских, страховых и т.п.;

NP - темп роста потребления товаров и услуг отечественного производства;

P - темп роста суммарного потребления индивидов и домохозяйств социальноэкономической системы;

$\mathrm{V}$ - темп роста суммарного объема производства товаров, работ, услуг в национальной экономике;

IS - темп роста численности индивидуальных предпринимателей и самозанятых в эконо- мике соответствующего уровня;

$\mathrm{Z}$ - темп роста суммарной численности занятых в экономической системе рассматриваемого уровня.

Таким образом, в состав показателей предлагаемой нами методики включены не только различные характеристики потребительского поведения индивидов социально-экономической системы, но и критерии, отражающие смежные процессы, такие как формирование и дифференциация доходов населения, экономическая активность субъектов хозяйствования, структурные процессы в области занятости и производительности труда.

Логика формирования эталонной последовательности показателей, включенных в состав предлагаемой автором методики, заключается в следующем:

1.1. В соответствии с предлагаемым подходом, максимальным должен быть темп снижения дифференциации доходов населения исследуемой экономической системы (государства в целом, региона, муниципального образования). Цель последовательного снижения уровня такого рода дифференциации (по критерию 1/ Kddmax), соответственно, рассматривается в качестве одной из наиболее приоритетных целей государственной социально-экономической политики.

Действительно, если в рамках определенной социально-экономической системы, например экономики государства, имеет место существенный и растущий уровень дифференциации доходов населения, в такого рода системе будут доминировать иррациональные или примитивные модели потребительского поведения. Последние будут реализовываться многочисленными представителями бедных слоев населения, для которых, по сути, единственным фактором потребительского выбора будет являться цена товара, а первые, иррациональные - формироваться узким кругом крайне богатых граждан, демонстрирующих избыточное, социально деструктивное интенсивное потребление предметов роскоши. Соответственно, важным условием активного развития рациональных и социально эффективных моделей потребительского поведения в экономике является максимизация удельного веса среднего класса в структуре населения, которая может быть достигнута только при условии последовательного уменьшения

" Калуби Дж. Совершенствование методов и моделей оценки эффективности воспроизводства основных фондов предприятий энергетической отрасли: Автореф. дис.к.э.н. - Спб., 2018. С. 17-18. 
уровня неравенства доходов.

1.2. Темп роста средних денежных доходов населения в системе координат предлагаемой нами методики должен превышать темп роста средней заработной платы занятых в экономике (DD>AZ). Выполнение данного соотношения будет свидетельствовать об ускоренном росте таких значимых элементов денежных доходов населения, как пенсии, доходы от самозанятости, доходы от предпринимательской деятельности и, соответственно, об относительном увеличении возможностей получателей такого рода доходов в плане формирования и реализации собственных моделей потребительского поведения.

1.3. Показатели доходов и заработной платы должны расти быстрее включенных в состав показателей предлагаемой методики показателей интенсивности потребления гражданами товаров, работ, услуг. Выполнение данного соотношения будет свидетельствовать об относительном росте сбережений граждан, за счет чего достигается как увеличение социальной стабильности, уверенности индивидов и домохозяйств в завтрашнем дне, так и рост возможностей реализации моделей потребления дорогостоящих благ в перспективе значительными группами домохозяйств (приобретение жилья, автотранспорта, оплата образования в рамках негосударственных программ высшего и среднего специального обучения и т.п.).

1.4. Темп роста потребления услуг в рамках предлагаемой методики должен опережать темп роста суммарного потребления $(\mathrm{S}>\mathrm{P})$. В целом, в соответствии, например, с подходом Дж. Ходжсона, который представляется достаточно логичным, чем больший удельный вес в структуре потребления населения занимают различного рода услуги (бытовые, цифровые, банковские, страховые и т.п.), тем более развитым является социум в целом". Действительно, активное потребление только товаров, но не услуг является индикатором либо высокого уровня бедности населения, либо крайней неразвитости такого значимого элемента современной постиндустриальной экономической системы, как рынок услуг населению.

1.5. Темп роста потребления отечественных товаров, работ, услуг должен превышать темп роста суммарного потребления (NP>P). Выполнение данного эталонного соотношения будет свидетельствовать об относительном увеличе- нии доли потребления отечественной продукции и услуг в общей структуре потребительских расходов физических лиц, что может быть следствием как относительно высокого уровня конкурентоспособности отечественных производителей, так и результативной реализации политики протекционизма на потребительском рынке.

1.6. Темп изменения суммарного потребления индивидов, в соответствии с эталонной последовательностью предлагаемой методики, должен опережать темп изменения производства товаров, работ, услуг в экономике в целом за тот же период(P>V). Выполнение данного соотношения будет свидетельствовать о превышении суммарного совокупного спроса над совокупным предложением национальных производителей, что, при прочих равных условиях, является значимым импульсом дальнейшей активизации отечественного производственного процесса.

1.7. Эталонное превышение темпов роста объема производства над темпами изменения численности занятых в экономике (V>Z) является индикатором относительного роста уровня производительности труда в рамках экономической системы. Отметим, что еще представители классической экономической теории, в первую очередь К. Маркс, доказали, что рост производительности труда в экономике является необходимым условием расширенного воспроизводства большинства экономических процессов, в т.ч. и прогрессивного развития национального потребительского рынка.

1.8. Эталонное превышение темпа изменения численности индивидуальных предпринимателей и самозанятых над общей численностью занятых в экономике (IS>Z) является индикатором относительного увеличения доли первых в общей структуре трудовых ресурсов. Выполнение данной пропорции является косвенным значимым индикатором долгосрочного увеличения емкости потребительского рынка экономической системы и роста качественного разнообразия представленных в его рамках товаров, работ и услуг.

2. Оценка фактических темпов изменения показателей, включенных в состав разработанной методики.

3. Расчет промежуточных коэффициентов ранговой статистики в соответствии с общей ме-

"Ходжсон, Дж. Экономическая теория и институты: Манифест современной институциональной экономической теории / Дж. Ходжсон // Пер. с англ. - М.: Дело, 2020. С. 152. 
тодологией НСП, отражающих степень соответствия фактического и эталонного темпов изменения рангов показателей методики, а именно:

$$
\begin{aligned}
& К c=1-6^{*} \Sigma \mathrm{O}^{2} /\left(\mathrm{H}^{*}\left(\mathrm{H}^{2}-1\right)\right) \\
& \text { Кк }=1-4 * \Sigma И /\left(\mathrm{H}^{*}(\mathrm{H}-1)\right.
\end{aligned}
$$

где Кс - промежуточный коэффициент ранговой статистики Спирмена;

Кк - промежуточный коэффициент ранговой статистики Кендалла;

О - отклонение фактического и эталонного рангов;

И - инверсия фактического и эталонного рангов (инверсия рангов равна положительному отклонению, при отрицательном значении отклонения принимается равной нулю);

н - общее количество показателей, включенных в состав методики (н=9).

4. Оценка эффективности потребительского поведения:

$$
Э П=(1+К c) *(1+K \kappa) * 100 \% / 4
$$

где ЭП - уровень эффективности потребительского поведения исследуемой социальноэкономической системы, измеряемый по шкале от $0 \%$ до $100 \%$.

5. Определение наиболее значимых резервов повышения эффективности потребительского поведения по критерию максимума инверсии рангов (в соответствии с общей статистической методологией НСП, предложенной И. М. Сыроежиным).

Апробируем предлагаемую методику комплексной оценки эффективности потребительского поведения на материалах национальной экономики России в целом за 2019-2020 гг. Исходные данные для апробации методики представлены в таблице 2.3.1.

Соответственно, на основании промежуточных статистических коэффициентов, приведенных в таблице 2.3.1, в системе координат предлагаемой методики оценим уровень эффективности экономического поведения населения РФ в 2020 г.:

$$
\text { ЭП }=(1-0,4)^{*}(1+0,11)^{*} 100 \% / 4=10,65 \%(2.3 .5)
$$

Таким образом, уровень эффективности потребительского поведения в национальной экономике РФ в целом в 2020 г. составил лишь $10,65 \%$, что, в соответствии с унифицированной шкалой предлагаемой методики, представляет собой неудовлетворительное значение. В значи- тельной степени подобная ситуация была обусловлена недостаточностью денежных ресурсов большинства групп населения, необходимых для осуществления достаточного потребления товаров и услуг.

Соответственно, основные направления повышения эффективности потребительского поведения в системе координат предлагаемой методики связаны не столько с регулированием национального потребительского рынка, сколько с совершенствованием развития смежных секторов национальных социальноэкономических отношений, в первую очередь политикой формирования и распределения доходов в РФ. Основные резервы повышения эффективности потребительского поведения, которые могут быть определены по критерию максимизации инверсии рангов, соответственно, являются;

- снижение уровня дифференциации доходов населения России (инверсия рангов 7), что за счет увеличения в его структуре среднего класса позволит последовательно увеличить потребление широкого спектра товаров и услуг повседневного спроса;

- обеспечение роста как реальных денежных доходов населения в целом, в т.ч. за счет дальнейшего прогрессивного развития института самозанятости, так и средней заработной платы (инверсии рангов 3 и 4), что, собственно, является объективной финансовой основой повышения эффективности потребительского поведения в национальной экономике;

- обеспечение дальнейшего роста результативности политики национального протекционизма, нацеленной на рост производства отечественных товаров, в первую очередь, в сегменте высокотехнологичной продукции народного потребления (инверсия рангов 2).

В целом, предлагаемая нами методика позволяет оценить эффективность потребительского поведения физических лиц в рамках экономической системы различного уровня (государство, регион, муниципальное образование) в контексте сопоставления параметров интенсивности изменения различных составляющих потребительского поведения с темпами развития смежных социально-экономических процессов, в первую очередь генерирования доходов и темпов изменения производительности труда и занятости, а также определить на данной основе наиболее значимые резервы повышения уровня результативности потребительского поведения. 
Таблица 2.3.1. Исходные данные для апробации предлагаемой методики на материалах экономики РФ, 2020 г. к 2019 г.

\begin{tabular}{|c|c|c|c|c|c|c|c|}
\hline Показатель методики & $\begin{array}{l}\text { Обозна- } \\
\text { чение }\end{array}$ & $\begin{array}{l}\text { Эталон- } \\
\text { ный ранг }\end{array}$ & $\begin{array}{l}\text { Темп } \\
\text { роста }\end{array}$ & $\begin{array}{l}\text { Факт. } \\
\text { ранг }\end{array}$ & $\begin{array}{l}\text { Отклоне- } \\
\text { ние }(\mathrm{O})\end{array}$ & $\mathrm{O}^{2}$ & \begin{tabular}{|} 
Инверсия \\
(И)
\end{tabular} \\
\hline $\begin{array}{l}1.1 \text { / темп роста коэффициен- } \\
\text { та дифференциации доходов } \\
\text { населения }\end{array}$ & $1 / \mathrm{KDD}$ & 1 & 0,94 & 8 & 7 & 49 & 7 \\
\hline $\begin{array}{l}\text { 2. Темп роста средних денеж- } \\
\text { ных доходов населения }\end{array}$ & $\mathrm{DD}$ & 2 & 0,97 & 5 & 3 & 9 & 3 \\
\hline $\begin{array}{l}\text { 3. Темп роста среднего уровня } \\
\text { заработной платы }\end{array}$ & $\mathrm{AZ}$ & 3 & 0,95 & 7 & 4 & 16 & 4 \\
\hline $\begin{array}{l}\text { 4. Темп роста потребления } \\
\text { услуг физическими лицами }\end{array}$ & S & 4 & 1,04 & 2 & -2 & 4 & 0 \\
\hline $\begin{array}{l}\text { 5. Темп роста потребления } \\
\text { товаров и услуг отечественного } \\
\text { производства }\end{array}$ & NP & 5 & 0,98 & 4 & -1 & 1 & 0 \\
\hline $\begin{array}{l}\text { 6. Темп роста суммарного по- } \\
\text { требления индивидов и домо- } \\
\text { хозяйств }\end{array}$ & $\mathrm{P}$ & 6 & 0,96 & 6 & 0 & 0 & 0 \\
\hline $\begin{array}{l}\text { 7. Темп роста суммарного } \\
\text { объема производства товаров, } \\
\text { работ, услуг в национальной } \\
\text { экономике }\end{array}$ & V & 7 & 0,93 & 9 & 2 & 4 & 2 \\
\hline $\begin{array}{l}\text { 8. Темп роста численности } \\
\text { индивидуальных предприни- } \\
\text { мателей и самозанятых }\end{array}$ & IS & 8 & 1,15 & 1 & -7 & 49 & 0 \\
\hline $\begin{array}{l}\text { 9. Темп роста суммарной чис- } \\
\text { ленности занятых }\end{array}$ & Z & 9 & 0,982 & 3 & -6 & 36 & 0 \\
\hline Сумма & $\mathrm{x}$ & $\mathrm{x}$ & $\mathrm{x}$ & $\mathrm{x}$ & $\mathrm{x}$ & 168 & 16 \\
\hline $\begin{array}{l}\text { Промежуточные статистиче- } \\
\text { ские коэффициенты }\end{array}$ & \multicolumn{7}{|c|}{$\begin{array}{c}\mathrm{Kc}=1-6 * 168 /(9 * 80)=-0,4 \\
\mathrm{Kk}=1-4 * 16 /(9 * 8)=0,11\end{array}$} \\
\hline
\end{tabular}

\section{Библиографический список}

1. Автономов В. Образ человека в политической экономии // М3 и МО. - 1990. - № 1. - С. 21.

2. Вебер М. Избранные произведения. - М.: Прогресс, 1990. - 36 с.

3. Гизятов И.И. Формирование и комплексная оценка эффективности политики ресурсосбережения в промышленности: Автореф. дис.к.э.н. - Казань, 2011. - 24c.

4. Грачева Т.А. Поведение экономического субъекта в условиях становления рыночных институтов / Дис. ... канд. экон. наук: 08.00.01. - М.: 2005. - 165 с.

5. Калуби Дж. Совершенствование методов и моделей оценки эффективности воспроизводства основных фондов предприятий энергетической отрасли: Автореф. дис.к.э.н. - Спб., 2018. 26с.

6. Леонтьев В. В. Экономические эссе. Теории, исследования, факты и политика. - М: Политиздат, 1990. - 53 с.

7. Сыроежин И. М. Система показателей эффективности и качества. - М.: Экономика, 1980.-192с.

8. Фахрутдинова Е. В. Диалектика потребностей человека// Экономические науки. 2009. № 57. С. 43-47.

9. Фахрутдинова Е.В., Васильев А.К. Потребности и качество жизни человека: аспекты взаимодействия. Экономические науки. 2009. № 59. С. 90-93.

10. Ходжсон, Дж. Экономическая теория и институты: Манифест современной институциональной экономической теории / Дж. Ходжсон // Пер. с англ. - М.: Дело, 2020. 464c.

11. Ядгаров Р.С. Истории экономических учении // Учеб. 3-е изд. - М.: ИНФРА-М, 2000. - 176 с.

12. Blanc S., Massaglia S., Borra D., Mosso A., Merlino V.M. Animal welfare and gender: a nexus in awareness and preference when choosing fresh beef meat? // Journal of Animal Science. - 2020. - Volume 19, Issue 1. - Pp. 410-420

13. Rondoni A., Asioli D., Millan E. Consumer behaviour, perceptions, and preferences towards eggs: A review of the literature and discussion of industry implications // Trends in Food Science and Technology. - 2020. - Volume 106. - Pp. 391-401. 
14. Testa F., Iovino R., Iraldo F. The circular economy and consumer behaviour: The mediating // Business Strategy and the Environment. - 2020. - Volume 29, Issue 8. - Pp. 391-401.

15. Nimri R., Patiar A., Jin X. The determinants of consumers' intention of purchasing green hotel accommodation: Extending the theory of planned behavior // Journal of Hospitality and Tourism Management. - 2020. - Volume 45. - Pp. 535-543.

16. Khanra S., Dhir A., Kaur P., Joseph R. P. Factors influencing the adoption postponement of mobile payment services in the hospitality sector during a pandemic // Journal of Hospitality and Tourism Management. - 2020. - Volume 46. - Pp. 26-39.

17. Fakhrutdinova E., Severyanov O., Shigabutdinov A., Fakhrutdinov R. The crisis of 1988 in Russia: political intervention and its implication//Life Science Journal. 2014. T. 11. № 6s. C. 442-447. 